\title{
Polycrystalline Silicon films obtained by hot-wire chemical vapour deposition
}

J. Cifre, J. Bertomeu, J. Puigdollers, M.C. Polo, J. Andreu

Laboratori de Física de Capes Fines (LFCF). Dept. Física Aplicada i Electrònica, Universitat de Barcelona. Avda. Diagonal 647. E-08028 Barcelona.

Tel. 34-3-4021145. Fax. 34-3-4021118. E-mail. UBAFEM01@puigmal.cesca.es

\section{A. Lloret}

Laboratoire de Physique des Interfaces et des Couches Minces, CNRS UPR A258, Ecole Polytechnique, F-91128 Palaiseau Cedex, France

Tel. 33-1-69333211. Fax. 33-1-69333006.

PACS numbers. 81.15

\section{ABSTRACT}

Silicon films were deposited at moderate substrate temperatures $\left(280-500{ }^{\circ} \mathrm{C}\right)$ from pure silane and a silane-hydrogen mixture $\left(10 \% \mathrm{SiH}_{4}, 90 \% \mathrm{H}_{2}\right)$ in a hot wire CVD reactor. The morphology, structure and composition of the samples were studied with Scanning Electron Microscopy, Transmission Electron Microscopy, Transmission Electron Diffraction, X-ray diffraction, Raman-spectroscopy and Secondary Ion Mass Spectrometry. The sample deposited at $500^{\circ} \mathrm{C}$ with pure silane has an amorphous structure, whereas the samples obtained from silane diluted in hydrogen have a polycrystalline structure even that grown at the lowest temperature $\left(280^{\circ} \mathrm{C}\right)$. Polycrystalline samples have a columnar structure with $0.3-1 \mu \mathrm{m}$ crystallite sizes with preferential orientation in [220] direction. Deposition rates depend on the filament-substrate distance and range from 9.5 to $37 \mathrm{~A} / \mathrm{s}$ for the polycrystalline samples. The high quality of the polycrystalline samples obtained makes the hot-wire technique very promising. Moreover, it is 
expected to be easily scaled up for applications to large area optoelectronic devices and to photovoltaic solar cells.

\section{Introduction}

Since early studies on hydrogenated amorphous silicon (a-Si:H) deposition using heterogeneous hot-wire chemical vapour deposition (HWCVD), also known as catalytic-CVD [1-4], much attention has been devoted to this method with the goal of obtaining good quality material, mainly for photovoltaic applications [5-8]. HWCVD technology has the advantage of allowing high deposition rates (10 A/s as reported in the case of a silane-germane gas mixture [9]). In this process the heated filament induces silane pyrolytic dissociations producing, in addition to silyl radicals, atomic hydrogen, which reacts with silane molecules to produce mainly $\mathrm{SiH}_{3}$ radicals [3].

As an alternative to a-Si:H thin films for the fabrication of solar cells, polycrystalline $\mathrm{Si}$ (poly-Si) films of 10-30 $\mu \mathrm{m}$ thickness have been suggested [10-12]. In fact, poly-Si films have a wide range of optoelectronic applications in large-area semiconductor devices, such as thin film transistors (TFT) used in active displays. Therefore, an effort is currently being directed to obtaining high-quality poly-Si thin films by low temperature deposition on glass. One of the methods, known as solid phase crystallization (SPC) [12-14], combines plasma-enhanced chemical vapour deposition (PECVD) of a-Si:H at moderate temperatures and long-time annealing in the $550-700{ }^{\circ} \mathrm{C}$ range. This technique has been used to obtain poly-Si solar cells made from a heterojunction with intrinsic thin layer (HIT) [14].

Attempts to obtain poly-Si fims by HWCVD using silane and silane-hydrogen mixtures have already been reported [15-17]. The most interesting result of these early experiments is the potential to grow these films, with good electronic properties, at low temperature $\left(<500{ }^{\circ} \mathrm{C}\right)$ and high deposition rates. This would be a definitive advantage over the SPC method, since it would obviate the need for post-annealing. 
Here we show that HWCVD may be used to obtain 10-30 $\mu$ m thick poly-Si at fast growth rates and moderate temperatures, thus allowing the use of standard glass substrates. A set of five samples obtained with different experimental conditions was studied with Scanning and Transmission Electron Microscopy (SEM and TEM), Transmission Electron Diffraction (TED), X-ray Diffraction (XDR), Raman Spectroscopy and Secondary Ion Mass Spectrometry (SIMS).

\section{Experimental}

Five films (HW1 to HW5) were obtained in the HWCVD reactor shown in Figure 1. The main deposition parameters are listed in Table 1. The filament, 1mm thick and $150 \mathrm{~mm}$ long, was folded in order to cover the whole sample surface homogeneously. In all experiments the filament temperature was set to $1600^{\circ} \mathrm{C}$ as measured by an optical pyrometer. Fussed silica substrates were placed on a graphite holder located close to the filament at a distance ranging from 1 to $4 \mathrm{~cm}$. The substrate temperature was measured by a calibrated thermocouple attached to the substrate holder. The calibration for substrate temperature was previously obtained using a second thermocouple attached to the substrate.

The HW1 sample was deposited from pure silane. The remaining samples were deposited from a mixture of $10 \%$ silane and $90 \%$ hydrogen. In all experiments the pressure was $21 \mathrm{~Pa}$. The silane flow ranged from 2-20 sccm (Table 1).

Before placing the substrates in the reaction chamber, the filament was heated to $2000^{\circ} \mathrm{C}$ and maintained at that temperature in a vacuum for 30 minutes. After that, the substrates were placed on the holder and the reaction chamber was evacuated to $2 \cdot 10^{-4} \mathrm{~Pa}$. For sample HW1, the filament was heated to $1600^{\circ} \mathrm{C}$ and then the chamber was filled with pure silane. For samples obtained from silane-hydrogen mixtures, the chamber was filled with hydrogen to the deposition pressure and then the filament was heated to $1600{ }^{\circ} \mathrm{C}$. For all experiments the silane was introduced when the substrate reached a stable temperature.

All films were morphologically and structurally characterized by SEM, TEM, TED, XDR 
and Raman Spectroscopy. SIMS was used for the study of tungsten contamination. For TEM and TED analysis, plane view and cross-section specimens were prepared. The Micro-Raman spectrometer is equipped with a $514.5 \mathrm{~nm}$ Ar laser focused on a spot with a diameter of $0.7 \mu \mathrm{m}$. X-ray diffraction analyses were performed in a powder diffractometer in the Debye-Sherrer geometry. The thicknesses were measured using a profilometer and SEM cross-section images.

\section{Results and discussion}

The study of the films obtained shows the possibility of growing large columnar crystalline structures at moderate temperatures and high deposition rates, and the influence on these structures of the silane dilution in hydrogen and of the substrate temperature. The growth rates and substrate temperature corresponding to all samples are shown in Table 1.

When the filament-substrate distance (d) was increased from 1 to $4 \mathrm{~cm}$, the substrate temperature $\left(\mathrm{T}_{\mathrm{S}}\right)$ decreased from $500^{\circ} \mathrm{C}$ to $280^{\circ} \mathrm{C}$. Moreover, the deposition rate decreased as $\mathrm{d}$ increased, due to the reduction of the solid angle of collection of active species and to gas phase losses during diffusion between the hot reaction zone and the substrate.

-1. Morphological and structural analysis

The effect of the hydrogen dilution has been studied by comparing two samples (HW1 and HW2). Sample HW1 was grown from pure silane and HW2 from silane diluted in hydrogen at the same $\mathrm{d}$ and $\mathrm{T}_{\mathrm{S}}$. The deposition rate of the former is four fold higher than that of the latter. The XRD spectrum (Fig. 2) of sample HW2 shows the main crystalline silicon diffraction peaks. Moreover, its Raman spectrum (Fig. 3) presents a narrow high intensity peak centered at $520 \mathrm{~cm}^{-1}$, which is characteristic of poly-Si [18]. The polycrystalline structure of the HW2 sample is therefore obvious. For sample HW1, the observation of wide low-intensity silicon diffraction peaks in XRD spectrum and broad enhancement at $480 \mathrm{~cm}^{-1}$ in Raman spectrum suggests a dominant amorphous 
phase.

The integrated Raman spectrum intensity of the crystalline part $\left(\mathrm{I}_{520}\right)$ relative to the intensity of the amorphous component $\left(\mathrm{I}_{480}\right)$ has been usually used to determine the fraction of crystallinity [19]. The absence of $480 \mathrm{~cm}^{-1}$ peak in Raman spectrum of HW2 sample reveals a dominant crystalline phase, whereas the absence of narrow peak at $520 \mathrm{~cm}^{-1}$ in $\mathrm{HW} 1$ spectrum confirms its amorphous nature.

The effect of substrate temperature in the $500-280^{\circ} \mathrm{C}$ range have been studied through the analysis of samples HW2, HW3, HW4 and HW5 obtained at the same pressure and $\mathrm{SiH}_{4} / \mathrm{H}_{2}$ fraction, but at different filament-substrate distance. The increase of this distance, in adittion of temperature change, has also produced a decrease in the growth rate.

In these experimental conditions, small differences have been observed on the cristallinity of the films obtained. The XRD and Raman spectra of all the samples show the characteristic peaks of crystalline structures (Fig. 2 and 3). The relative intensities of diffraction peaks in XRD spectra of these samples are similar. Moreover, when comparing these spectra with such of randomly oriented silicon, a [220] preferential orientation perpendicular to the substrate is observed in all samples.

The morphology and structure of polycrystalline samples (HW2, HW3, HW4 and HW5) were studied by SEM. Figure 4 shows the cross-sectional and top view of sample HW2. The cross-sectional views for all samples reveals a clear columnar structure. The top view for all samples show a structure formed by grains. Sample obtained at higher temperature (HW2) presents the larger grains with sizes ranging from 0.5 to $1 \mu \mathrm{m}$. For the other samples the grain sizes are smaller. This effect could be attributed to differences of substrate temperature $\left(T_{\mathrm{S}}\right)$ or of thicknesses of the samples.

In order to obtain a more detailed characterization of crystalline microstructures, a TEM and TED study of sample HW3 was carried out (Fig. 5, 6 and 7). The cross-sectional views confirm the columnar crystal growth already observed by SEM. Crystal columns are widely observed (Fig. 5a). In Figure 5b, a twinned crystal can be observed. The extension of the twin allows us to outline the 
size of the cristalline columns, which is larger than the view wide $(1.3 \mu \mathrm{m})$. The TED patterns of the cross section of sample HW3 (Fig. 6a and 6b) obtained from a selected area of $1 \mu \mathrm{m}$ diameter consist of regulars spots whereas the diffraction rings, typical of polycrystalline material with small crystals, were not seen (Fig. 6a) or very weak (Fig. 6b). Such diffraction patterns showing single zone axis reflections (Fig. 6a zone axis [-111] and Fig. 6b zone axis [-112]) therefore corroborate the growth of films with large silicon crystals at $\mathrm{T}_{\mathrm{S}}=400^{\circ} \mathrm{C}$.

In order to find out the growth direction of the crystals, a plan-view TEM study, using an incident beam perpendicular to the substrate, was performed (Fig. 7a and 7b). The crystals are needle shaped and range from 0.3 to $1 \mu \mathrm{m}$ in lenght (Fig. 7a). Nanodiffraction patterns of most tested crystals show a [110] orientation (Fig. 7b) in agreement with the results of X-ray diffraction. Moreover, nanodiffraction patterns obtained along the length of the crystals always show the same zone axis [110], which confirms monocrystallinity of the grains.

\section{-2. Study of tungsten contamination}

Most of optoelectronic devices require a great semiconducting material purity. The study of sample contamination during the growth is therefore of great interest. In the present experiment, the main contamination source comes from the $1 \mathrm{~mm}$ diameter tungsten heated wire, placed close above the substrates. This contamination can also depend on the deposition process described in experimental section. Tungsten impurity concentrations $>10^{15} \mathrm{~cm}^{-3}$ can considerably reduce the conversion efficiency of polycrystalline solar cells [20].

In order to elucidate the presence of tungsten in the present studied samples, SIMS analysis were performed by using an "atomika A-DIDA 3000-30" ion microprobe. $\mathrm{O}^{+2}$ was used as primary beam to etch samples. The ions were accelerated to $15 \mathrm{kev}$ with a primary ion current of $1 \mu \mathrm{A}$.

The detection sensitivity of tungsten, which is supposed in low concentrations, was enhanced by adjusting the etching beam parameters : type of ions, acceleration voltage and beam current. $\mathrm{O}^{+2}$ was preferred to $\mathrm{Ar}^{+}$as primary beam, because produces a large ionization 
enhancement effect. Likewise, high acceleration voltage of the primary beam enhances the ionization ratio, and finally, a high primary ion beam current causes higher etching rates increasing the secondary ion current and consequently the detection sensitivity. The secondary ion optics parameters were also adjusted to improve transmission of high masses to the quadrupolar analyser.

SIMS analysis of films was carried out in mass spectra mode in the range of 179 to $188 \mathrm{amu}$ covering the tungsten isotope masses. All the samples gave a very similar spectra. The spectra show very low intensity signal for the different tungsten isotopes and the natural isotopic occurrence of tungsten isotope signals was not found. The tungsten signal intensity was in all the samples for all the tungsten isotopes lower than $1 \mathrm{c} / \mathrm{s}$, the same order of magnitude found in the background signal of the analyser in the scanned mass range.

From these results we can conclude that tungsten amount, in present studied samples, is below the detection limit of the SIMS. With the current working parameters the detection limit of tungsten in silicon is in the order of $10^{16} \mathrm{~cm}^{-3}$, so that the maximum amount of tungsten is $<1 \mathrm{ppm}$.

\section{- 3. Discussion on the mechanism of film growth.}

It is not possible, in the framework of this preliminary work, to completely describe the present crystallisation mechanism. Only some features can be pointed out, taking into account that the hot wire plays two roles: dissociating the gas and supplying energy for the crystallization.

- The role of hydrogen

It is generally accepted $[3,4]$ that a heated wire induces pyrolytic dissociation of silane and hydrogen molecules, mainly following the reactions:

$$
\begin{array}{llll}
\mathrm{SiH}_{4} & \text { + heated wire } & ----> & \mathrm{Si}+4 \mathrm{H} \\
\mathrm{SiH}_{4} & + \text { heated wire } & ----> & \mathrm{SiH}_{3}+\mathrm{H} \\
\mathrm{H}_{2} & \text { + heated wire } & ----> & 2 \mathrm{H}
\end{array}
$$


The dissociation rate of these reactions depends on the silane and hydrogen densities in the gas as well as on the filament decomposition efficiency, which increases with temperature in the range $600-1800{ }^{\circ} \mathrm{C}$. As the filament temperature in the present experiment is $1600{ }^{\circ} \mathrm{C}$, reaction (1) is the dominant mechanism of silane dissociation and therefore an appreciable flux of Si and $\mathrm{H}$ radicals and a smaller one of $\mathrm{SiH}_{3}$ will diffuse to the substrate [3]. In transit, these radicals interact mainly according to the following reactions:

$$
\begin{array}{llll}
\mathrm{H}+\mathrm{SiH}_{4} & ------> & \mathrm{SiH}_{3}+\mathrm{H}_{2} \\
\mathrm{Si}+\mathrm{SiH}_{4} \text {-------> } \mathrm{Si}_{2} \mathrm{H}_{2}+\mathrm{H}_{2} \quad\left(\text { or } 2 \mathrm{SiH}_{2}\right)
\end{array}
$$

The contribution to the film growth of the species produced in the gas phase reactions (4) and (5) is not significant at low silane pressure but increases with pressure. The reactions of Si in the gas phase at high silane pressures gives as a result reactive polymers of stable molecules such as disilane. The $\mathrm{SiH}_{3}$ radicals produced in (2) and (4), are not able to react with $\mathrm{SiH}_{4}$ and the reaction rate of $\mathrm{Si}$ atoms with $\mathrm{H}_{2}$ producing $\mathrm{SiH}_{2}$ seems to be negligible [3]. Therefore the main film precursors are expected to be $\mathrm{Si}$ and $\mathrm{H}$ at low pressure and $\mathrm{Si}, \mathrm{H}, \mathrm{SiH}_{3}$ and polymers at higher pressure.

In the present study, when silane diluted in hydrogen is used, the silane partial pressure is 2.1 $\mathrm{Pa}$ and the total gas pressure is $21 \mathrm{~Pa}$. As these experimental conditions are not very different from those reported in the 0.5 Pa silane pressure HWCVD study [3], we expect in our case, a film precursor composition of $\mathrm{Si}$ and $\mathrm{H}$ but with slightly higher amount of $\mathrm{SiH}_{3}$ radicals produced not only by reaction (2) but also (4). In experiments with higher silane pressure, similar to those reported in [2], the precursors are dominated by the gas phase reactions, and therefore a high $\mathrm{SiH}_{3}$ contribution is expected.

The increase of hydrogen partial pressure in mixtures containing a few Pa silane partial pressure contribute to an increase in atomic hydrogen precursors via reaction (3), and consequently 
$\mathrm{SiH}_{3}$ precursors via reaction (4). The crystalline structures observed in the present study represent growth from $\mathrm{Si}$ radicals and, to smaller extent, $\mathrm{SiH}_{3}$ and $\mathrm{Si}_{2} \mathrm{H}_{2}$ together with a very large contribution of $\mathrm{H}$ atoms. When $21 \mathrm{~Pa}$ pure silane pressure is used without $\mathrm{H}_{2}$, the density of $\mathrm{H}$ precursors is reduced while the $\mathrm{SiH}_{3}$ and $\mathrm{SiH}_{2}$ densities could be significant. This suggests that the obtention of poly-Si structures could depend on the ratio $\mathrm{H} / \mathrm{Si}_{\mathrm{m}} \mathrm{H}_{\mathrm{n}}$ of species contributing to film growth. Of course molecular and/or atomic hydrogen can be involved in surface reactions, acting in different processes of the film condensation, such as nucleation by changing the surface reactivity, or in microepitaxial growth. Further experiments aimed at the optimization of silane and hydrogen partial pressures could lead an understanding of the role of hydrogen in the deposition of poly-Si film structures with larger crystal grains.

- The role of filament radiation.

A crystallization process requires thermal energy, furnished, in the present experiments, by the heated filament itself, emitting a large amount of IR and visible radiation. This radiation could favor the crystallization process in a more efficient way than the subtrate holder heating commonly used in PECVD. Moreover, it is interesting to note that the temperature gradient across the film is inverted for the present HWCVD process with respect to a PECVD process. In the first case, the temperature decreases from the substrate to the top of deposited films. In PECVD, the opposite is true. The filament radiation impinging on the substrate depends on the filament temperature and on the filament-substrate distance. These considerations suggest that an interesting study to elucidate HWCVD crystallization would be, by using substrate substrate heating, the comparison of films deposited at the same substrate temperature but different filament-substrate distances and different deposition rates.

- The role of the deposition rate.

It is well know that the deposition rate is an important parameter governing the structural properties of growing a-Si:H films. Moreover, in PECVD, the transition from amorphous to 
microcrystalline growth is only obtained at very low deposition rates $(<1 \mathrm{~A} / \mathrm{s})$ under $\mathrm{H}_{2}$ dilution. The present experiments, where the growth rates are much higher (9.5-37 A/s for samples showing polycrystalline structures) are not extensive enough to allow us to outline the effect of deposition rate on the polycrystalline growth properties. This effect is certainly much smaller than in the case of the hydrogen dilution, but its optimization culd allow the obtention of better Si polycrystalline films.

Finally it is interesting to note that since a $10 \mu \mathrm{m}$ film thickness was obtained with polycrystalline structures, it is possible to envisage thicker films, up to a thickness of $30 \mu \mathrm{m}$ or more.

\section{Conclusions}

Morphological and structural studies performed with XRD, Raman-spectroscopy, SEM, TEM, TED show that poly-Si films can be obtained in a HWCVD reactor when silane diluted in hydrogen is used as gas precursor. The dilution in hydrogen appears to be essential since a-Si:H films are obtained with pure silane, in identical deposition conditions.

A columnar crystalline structure with $0.3-1 \mu \mathrm{m}$ crystallite sizes was observed with preferential orientation in direction [220]. In all polycrystalline samples, crystal columns extend from the substrates to the top of the films.

The growth rate of poly-Si films ranges from $9.5 \mathrm{~A} / \mathrm{s}$ to $37 \mathrm{~A} / \mathrm{s}$.

The maximum amount of tungsten impurity concentration in the poly-Si samples was estimated to be $10^{16} \mathrm{~cm}^{-3}$ by SIMS analysis.

The results of this preliminary study of HWCVD applied to the deposition of poly-Si appear very promising. Provided that optical and electronic properties prove satisfactory, one can foresee the possibility of fabricating efficient polycrystalline solar cells of low cost and large area as well as other optoelectronic devices.

Nevertheless an important work has to be accomplished in order to understand the growth 
mechanisms, to get a good parameter optimization and to develop optoelectronic devices.

\section{Acknowledgements}

The authors wish to acknowledge Dr. F. Peiró for TEM analysis and Dr. F. López for SIMS analysis. This work was supported by the DGICYT of the Spanish Government under programmes PB89-0236 and MAT93-0703-C03-02.

\section{References}

1. H. Wiesmann, A. K. Ghosh, T. McMahon, M Strongin: J. Appl. Phys. 50, 3752 (1979)

2. H. Matsumura: Jpn. J. Appl. Phys. 25, L949 (1986)

3. J. Doyle, R. Robertson, G. H. Lin, M. Z. He, A. Gallagher: J. Appl. Phys. $\underline{64}$, 3215 (1988)

4. H. Matsumura: J. Appl. Phys. $\underline{65}, 4396$ (1989)

5. A. H. Mahan, J. Carapella, B. P. Nelson, R. S. Crandall, I. Balberg: J. Appl. Phys. 69, 6728 (1991)

6. C. Horbach, W. Beyer, H. Wagner: J. of Non-crystalline Solids 137\&138, 661 (1991)

7. P. Papadopulos, A. Scholz, S. Bauer, B. Schroder, H. Oeschner: J. of Non-crystalline Solids 164-166, 87 (1993)

8. R. Zedlitz, F. Kessler, M. Heintze: J. of Non-crystalline Solids 164-166, 83 (1993)

9. H. Matsumura: Mat. Res. Soc. Symp. Proc., Vol. 118 (1988) pp. 43-48.

10. P. Campbell, M.A. Green: IEEE trans. Electron Device, ED-33, 234 (1986)

11. A. Luque, I. Tobius: Int. J. Solar Energy, $\underline{6}, 105$ (1988)

12. T. Matsuyama, K. Wakisaka, M. Kameda, M. Tanaka, T. Matsuoka, S. Tsuda, S. Nakano, Y. Kishi, Y. Kuwano: Jpn. J. Appl. Phys. 29, 2327 (1990)

13. T. Matsuyama, M. Taguchi, M. Tanaka, T. Matsuoka, S. Tsuda, S. Nakano, Y. Kuwano: Jpn. J. Appl. Phys. 29, 2690 (1990) 
14. T. Matsuyama, M. Sasaki, M. Tanaka, K. Wakisaka, S. Tsuda, S. Nakano, Y. Kishi, Y. Kuwano: 6th Int. Photovoltaic Conference Science and Engineering Conference, New Delhi, India (1992) pp. 753-758.

15. H. Matsumura: Jpn. J. Appl. Phys. 푸, L1522 (1991)

16. H. Matsumura, Y. Hosoda, S. Furukawa: Mat. Res. Symp. Proc. Vol. 283 (1993) pp. 623-628.

17. R. O. Dusane, Suvarna R. Dusane, V. G. Bhide, S.T. Kshirsagar: Appl. Phys. Lett. 므, 2201 (1993)

18. F.H. Pollak: Analytical Raman Spectroscopy, 1st. edn. (John Wiley \& Sons, New York 1991) pp. 137-214.

19. R. Tsu, J. Gonzalez-Hernandez, S.S. Chao, S.C. Lee, K. Tanaka: Appl. Phys. Lett. 40, 534 (1982).

20. M. Rodot: Filières et Materiaux, le Silicium cristallin. Physique et Technologie de la conversion photovoltaïque (direction B. Equer). Vol. 1, (UNESCO, Ellipses 1993) p. 139. 
Table 1. Experimental parameters.

\begin{tabular}{ccccccc} 
Sample & $\begin{array}{c}\mathrm{SiH}_{4} \\
(\mathrm{sccm})\end{array}$ & $\begin{array}{c}\mathrm{H}_{2} \\
(\mathrm{sccm})\end{array}$ & $\mathrm{d}(\mathrm{mm})$ & $\mathrm{T}_{\mathrm{S}}\left({ }^{\circ} \mathrm{C}\right)$ & $\begin{array}{c}\text { Growth rate } \\
(\mathrm{A} / \mathrm{s})\end{array}$ & Thickness $(\mu \mathrm{m})$ \\
\hline HW1 & 20 & 0 & 10 & 500 & 166 & 12.5 \\
HW2 & 2 & 18 & 10 & 500 & 37.1 & 7.8 \\
HW3 & 2 & 18 & 20 & 400 & 22.8 & 4.8 \\
HW4 & 2 & 18 & 30 & 330 & 15.2 & 3.2 \\
HW5 & 2 & 18 & 40 & 280 & 9.5 & 2.0 \\
\hline
\end{tabular}


Figure captions:

Fig. 1.Cross section of the heated filament reactor.

Fig. 2.XRD spectra of the samples deposited with $\mathrm{H}$ dilution at lowest $\mathrm{T}_{\mathrm{S}}=280^{\circ} \mathrm{C}$ (HW5) and higher $\mathrm{T}_{\mathrm{S}}=500^{\circ} \mathrm{C}(\mathrm{HW} 2)$ temperatures and with pure silane (HW1).

Fig. 3.Raman spectra of the deposited samples. The samples HW2 up to HW5, deposited with H dilution, present the characteristic peak of poly-Si centered at $520 \mathrm{~cm}^{-1}$.

Fig. 4.SEM micrographs of surface (1) and cross sections (2) of sample HW2 $\left(\mathrm{T}_{\mathrm{S}}=500^{\circ} \mathrm{C}\right)$.

Fig. 5.Cross-sectional TEM micrograph of HW3 sample showing the columnar microstructure (a) and a twinned silicon crystal (b).

Fig.6. a) Diffraction pattern obtained in selected area diffraction (SAD) mode from the cross section of HW3 sample. Spots corresponding to the single zone axis [-111] of silicon can be seen ( $\mathrm{T}$ denotes transmitted spot).

b) Diffraction pattern obtained in SAD mode from the cross section of HW3 sample that correspond to the single zone axis [-112].

Fig. 7.a) TEM brigh field micrograph of a silicon grain viewed along the [110] direction in a plan-view of HW3 sample.

b) Nano-diffraction pattern obtained with a beam of $2 \mathrm{~nm}$ diameter focused at the center of the grain shown in a). 


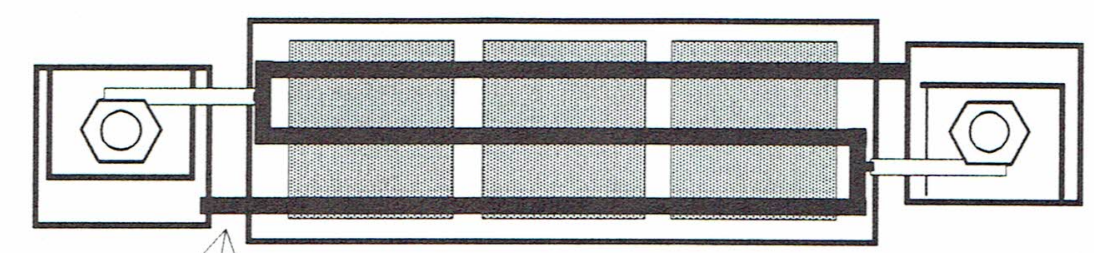

Filament

Gas inlet

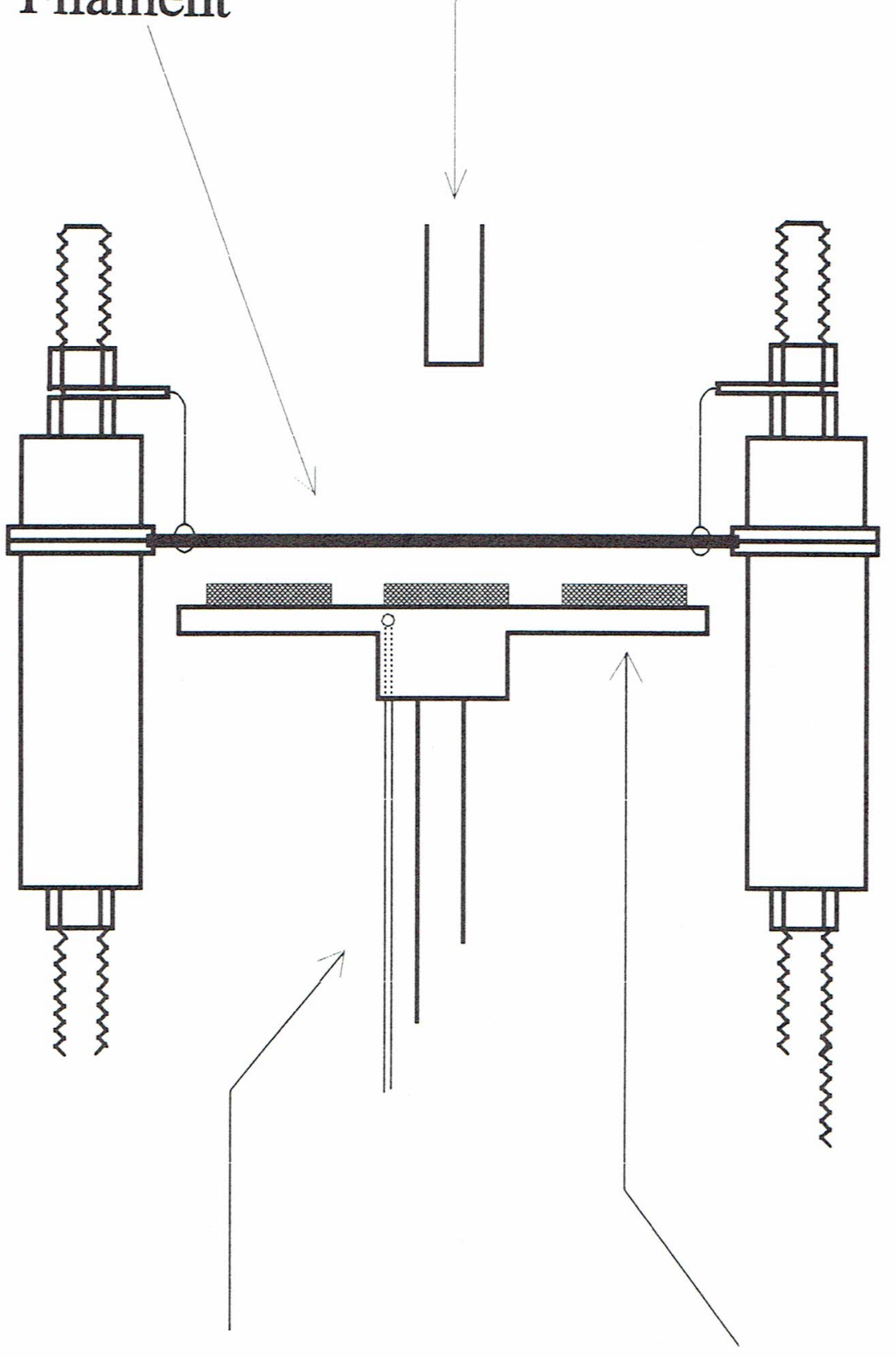

Termocouple Substrate holder 


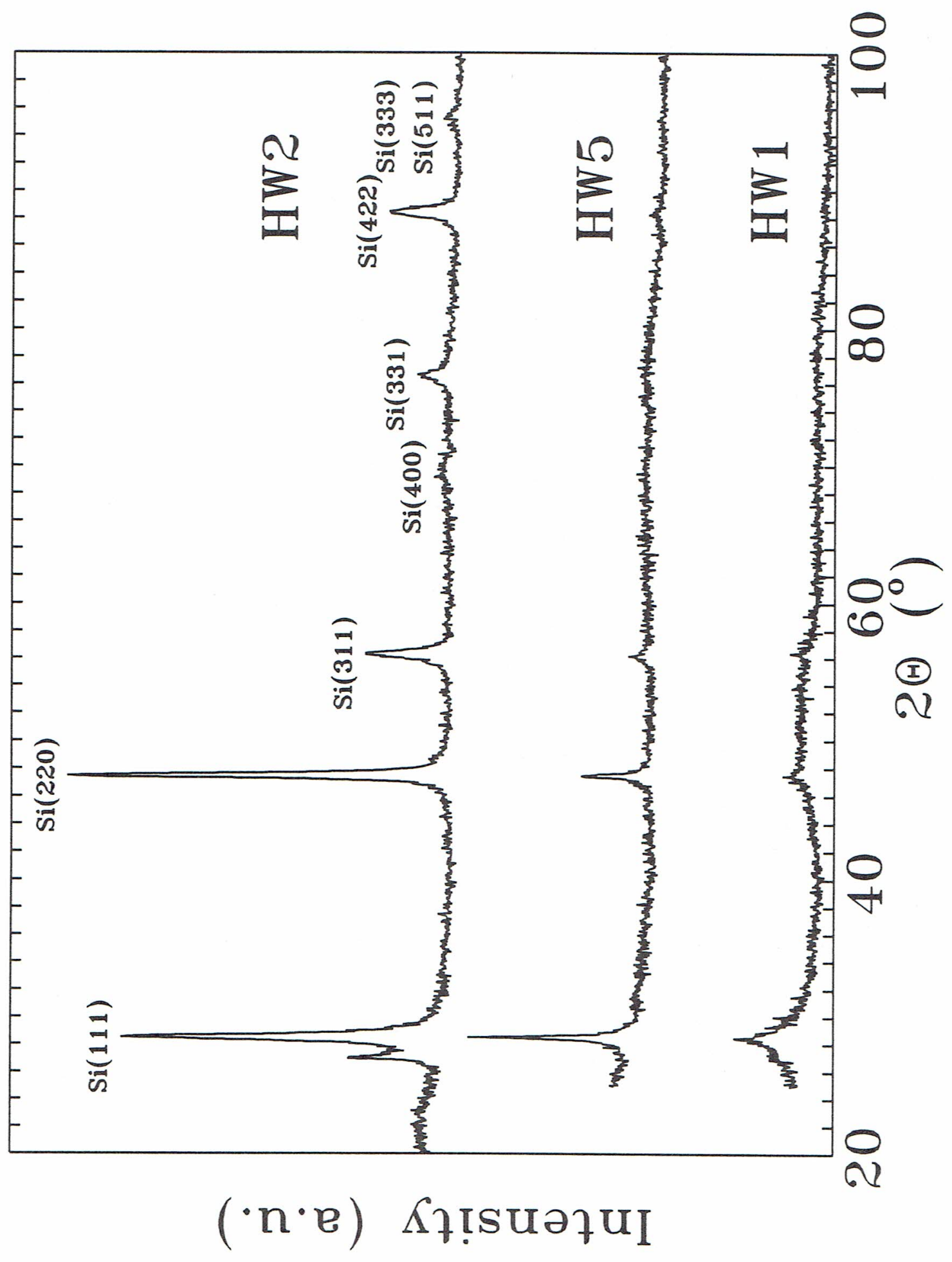




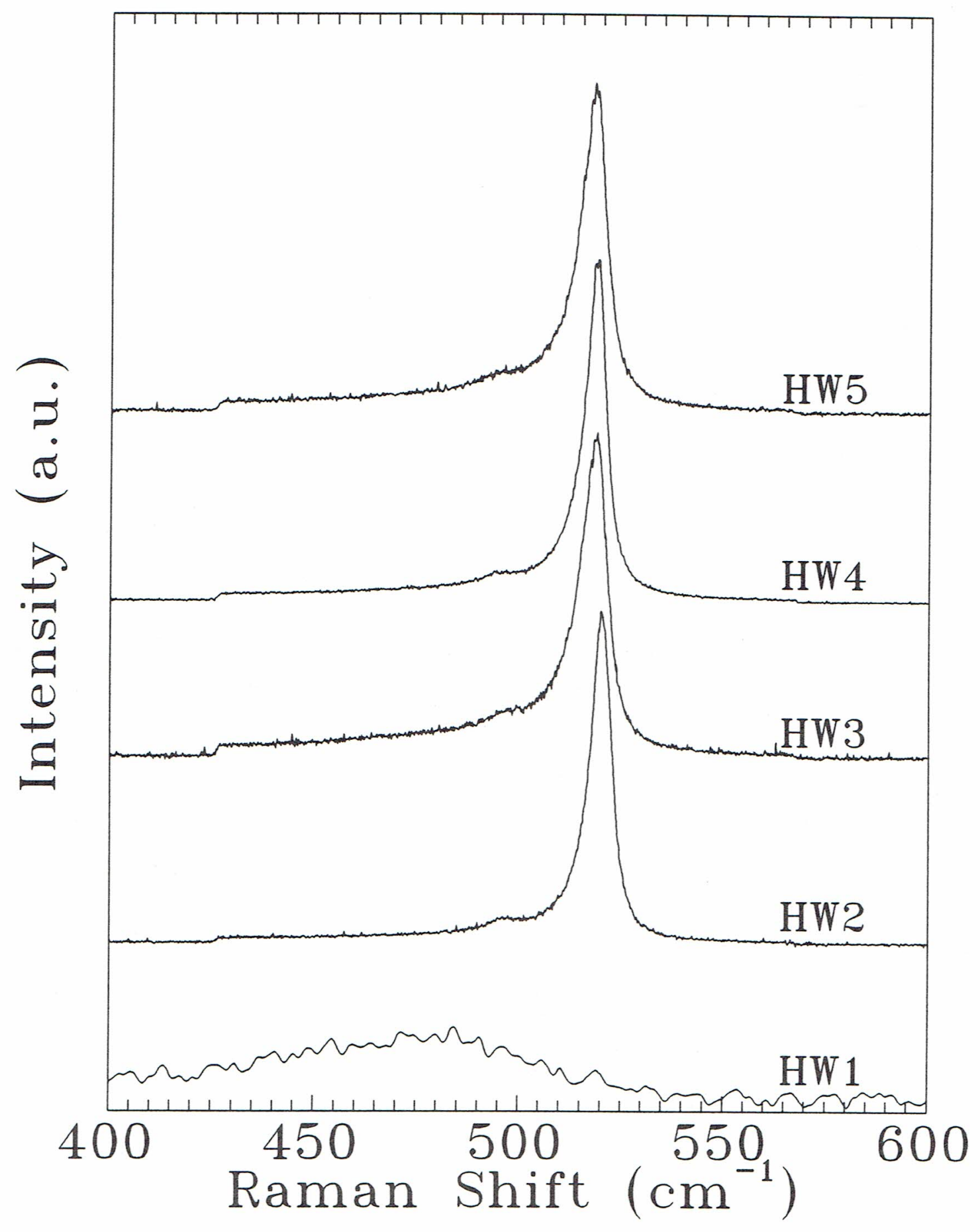




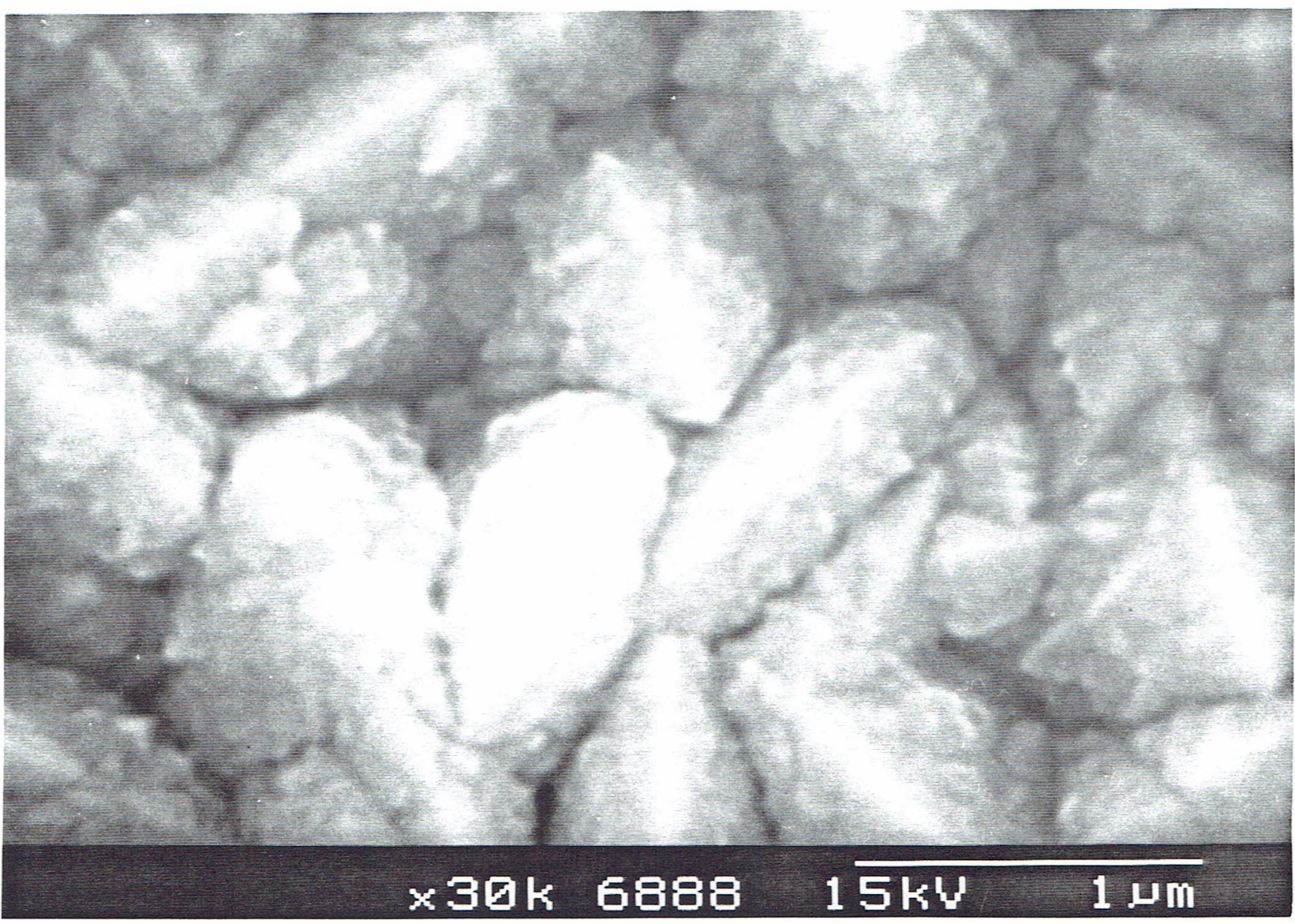

Fig $41 a$

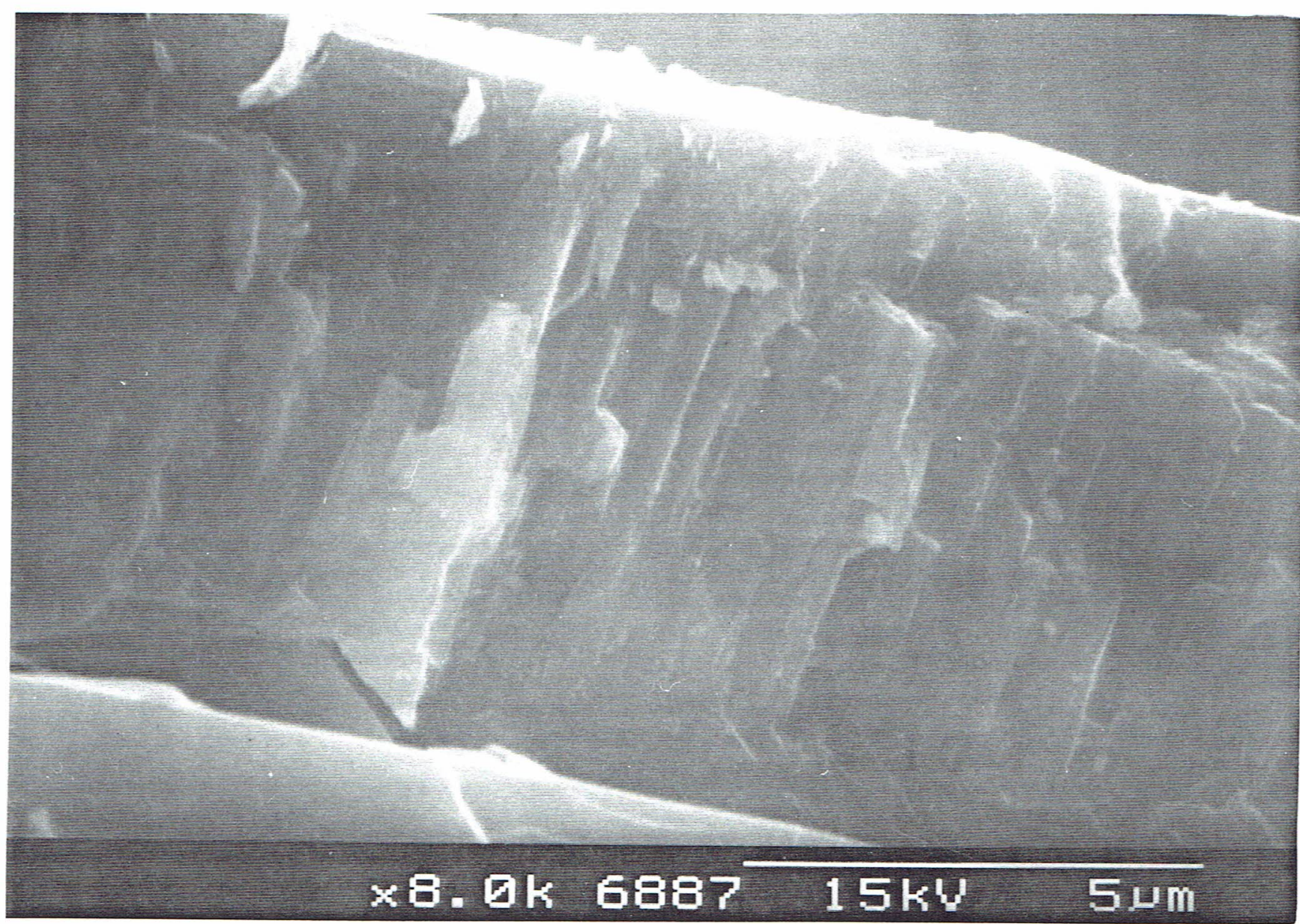

$\operatorname{tig}_{4} 2 a$ 


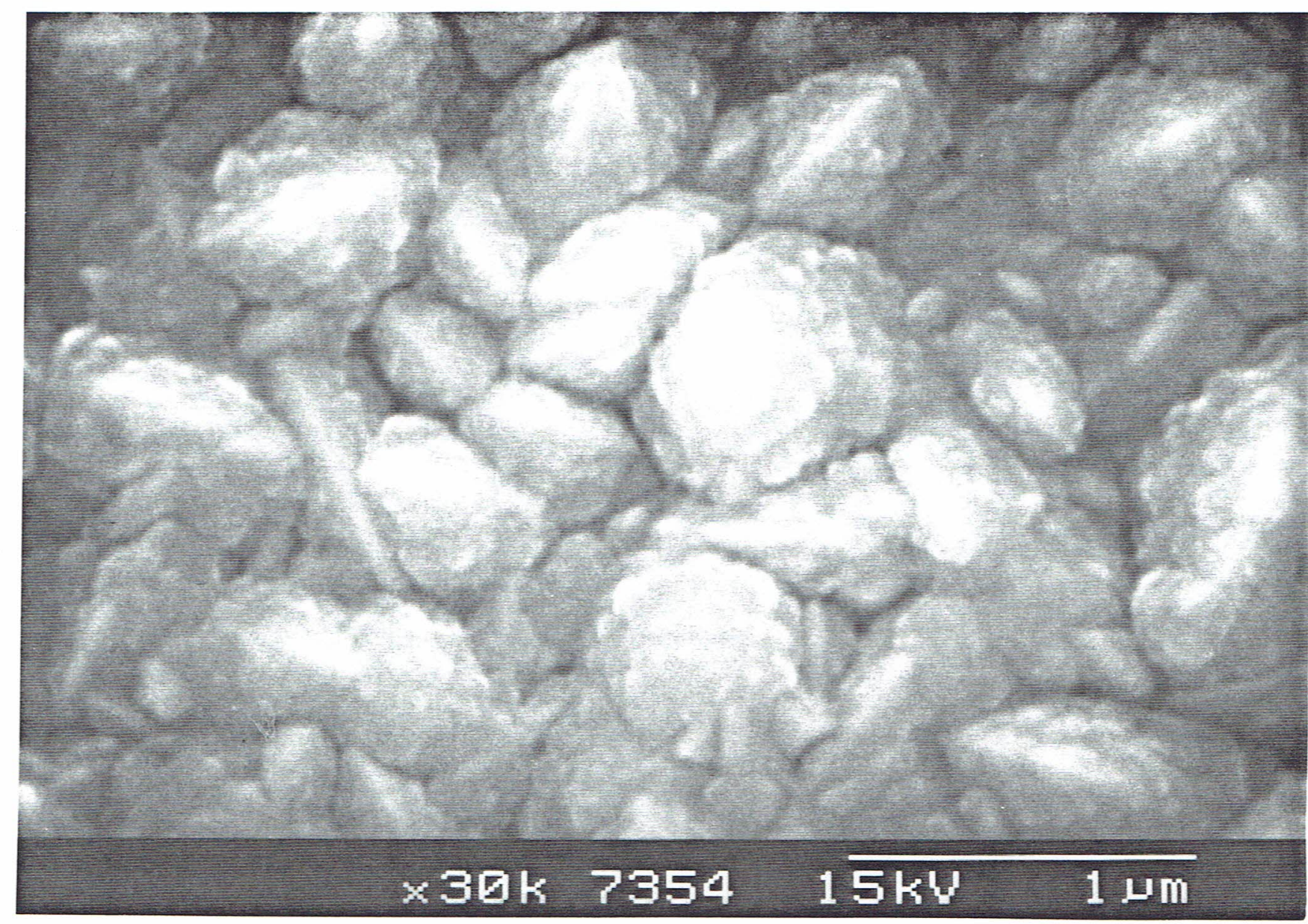

Fin 415

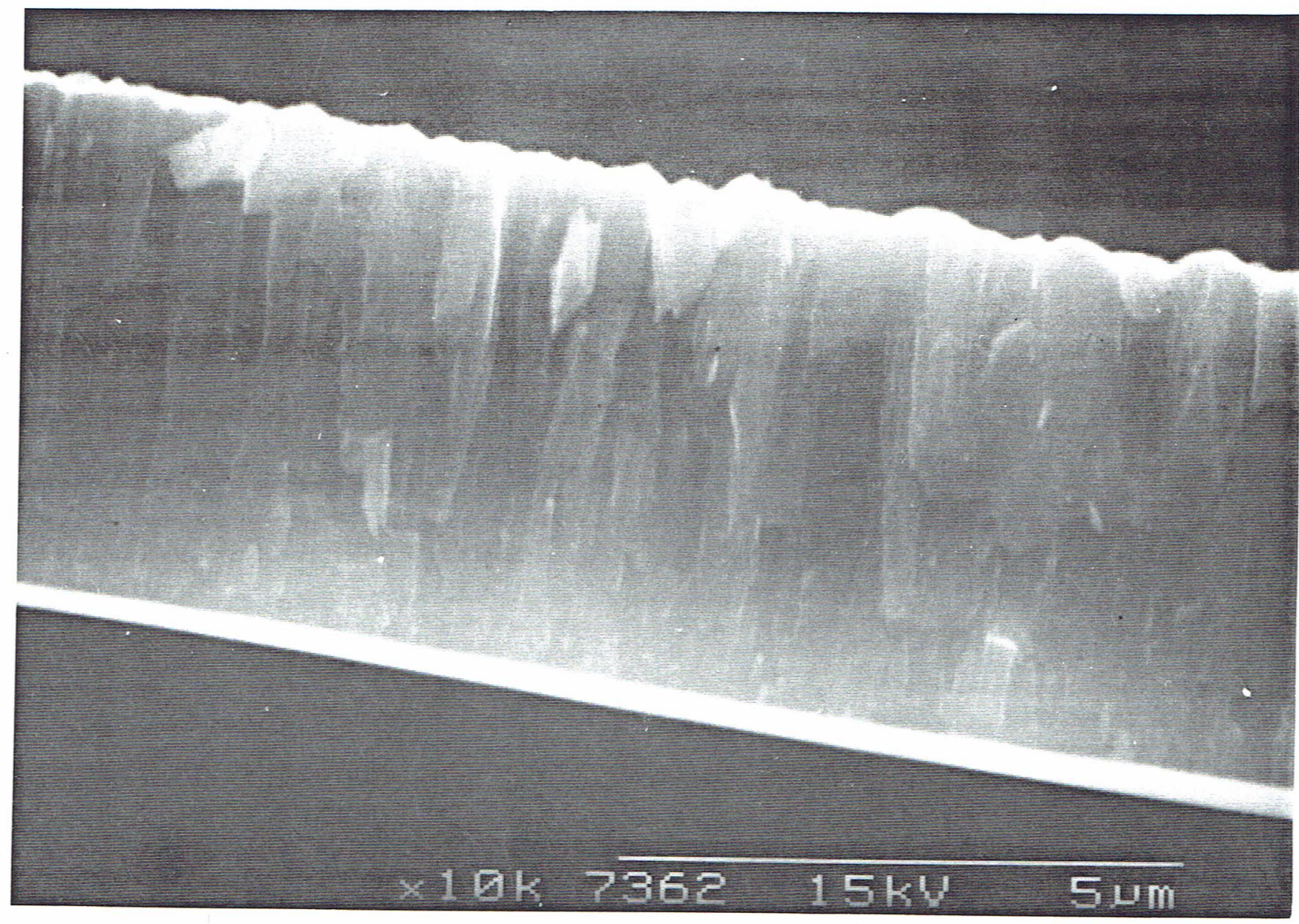




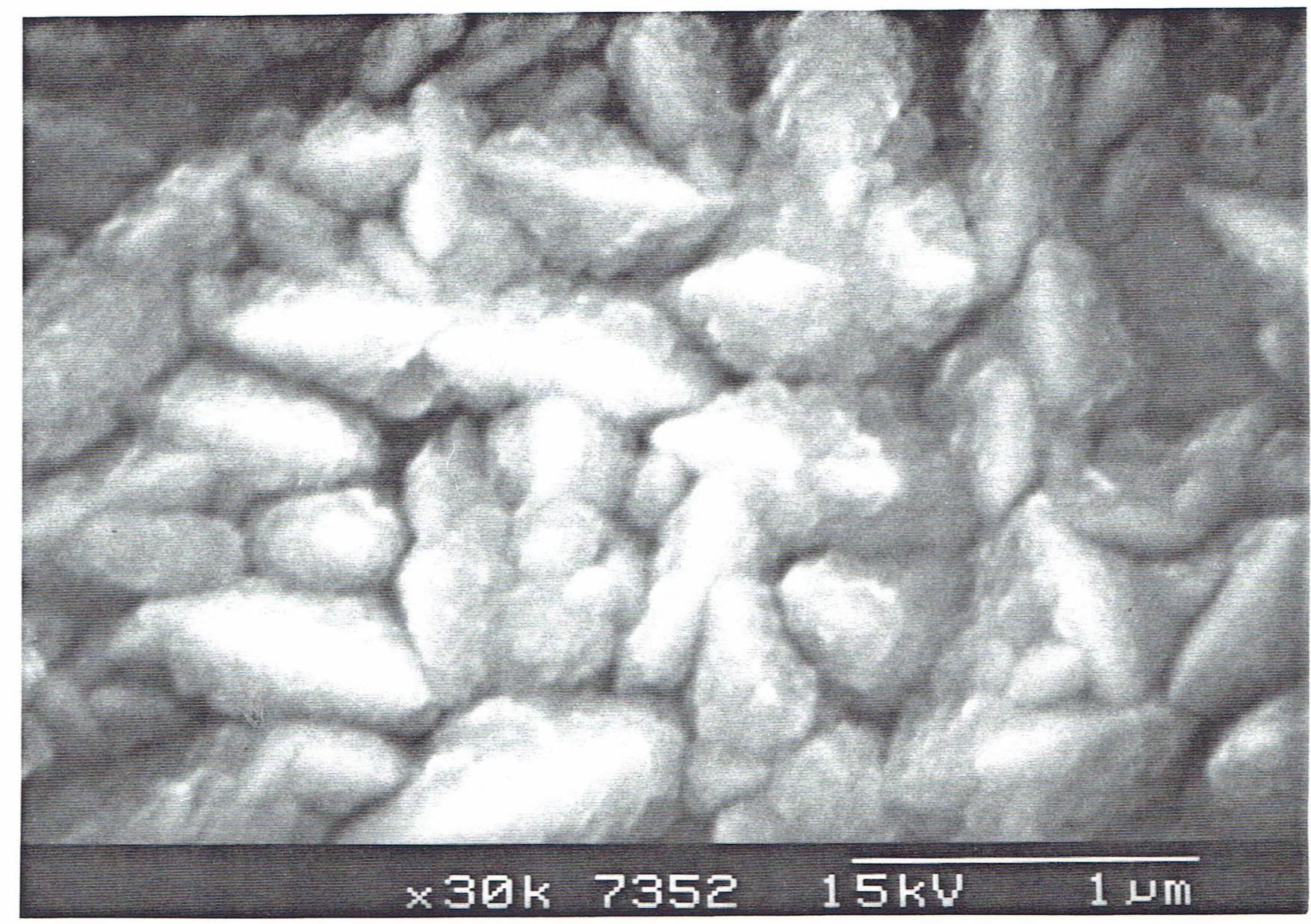

Fig b 10






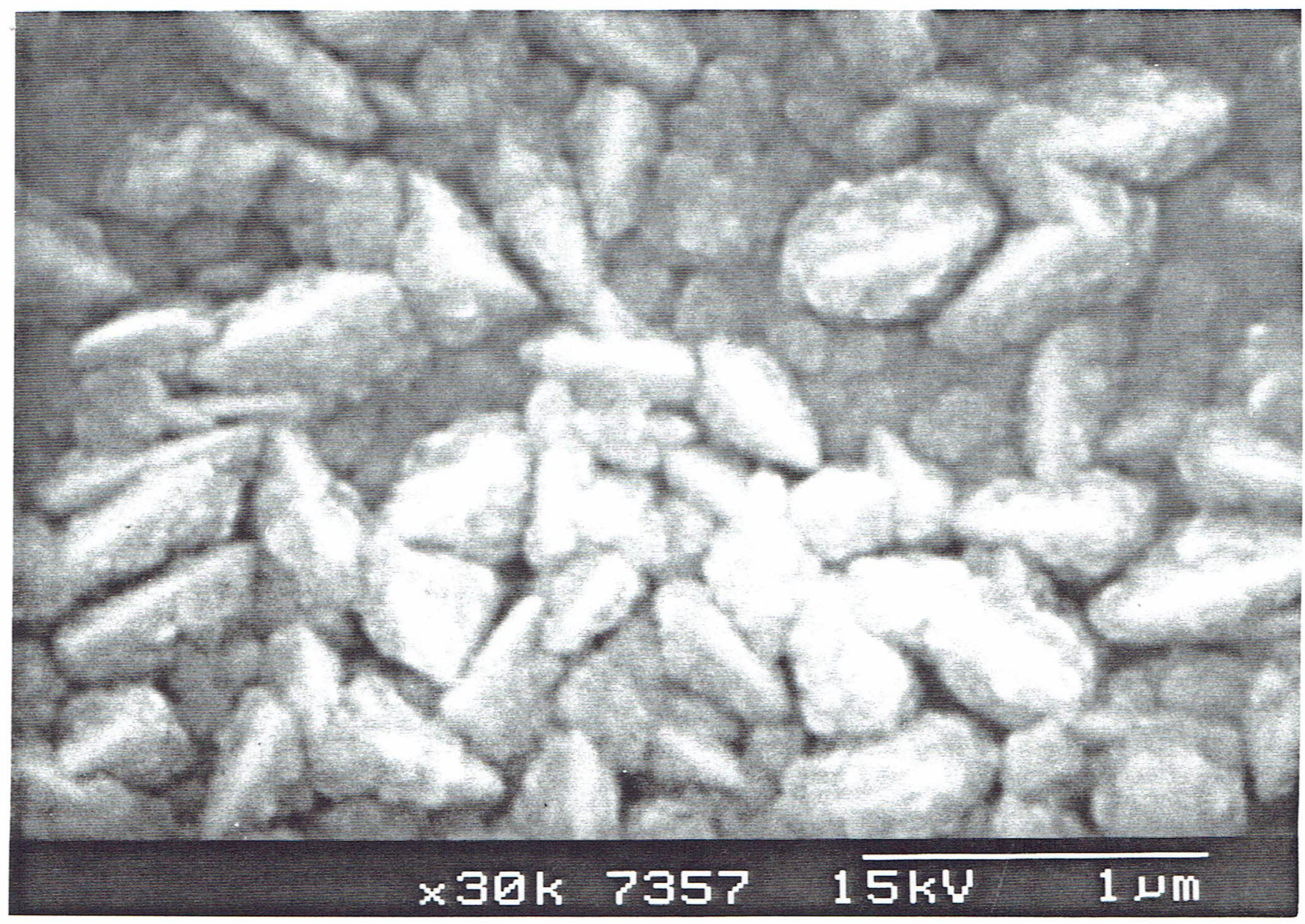

Fig $41 \mathrm{~d}$ 


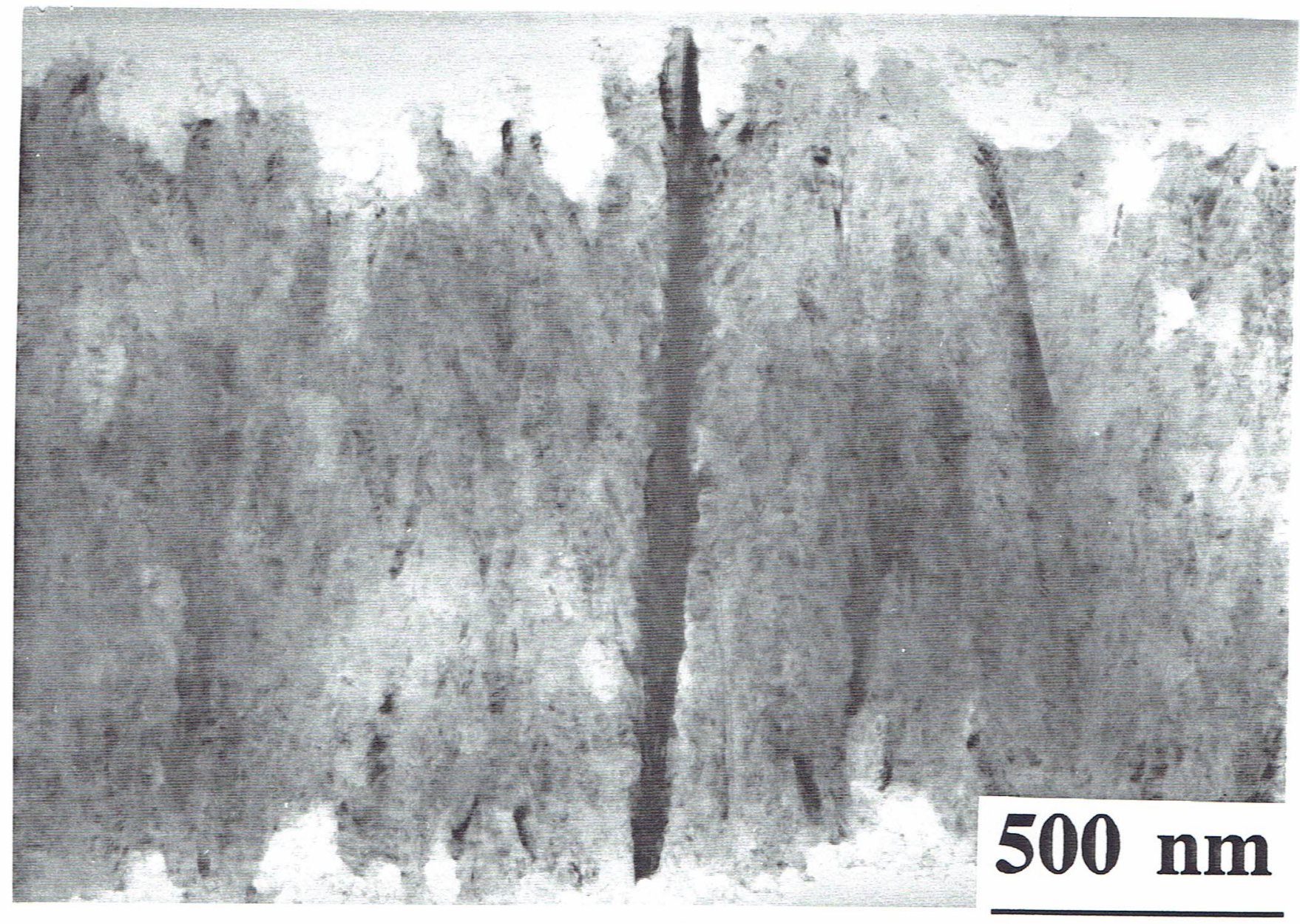
Fig $5 \approx$

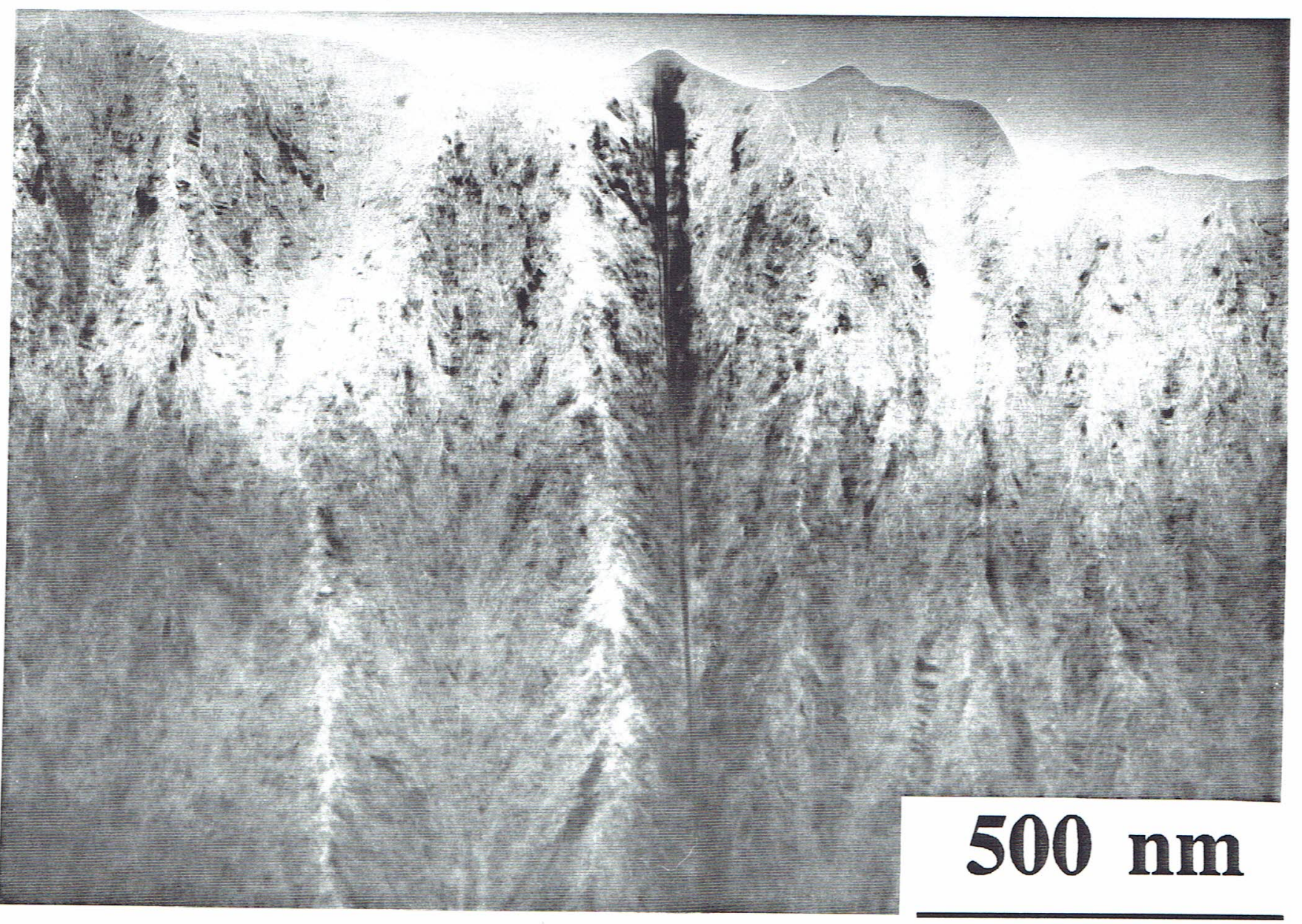




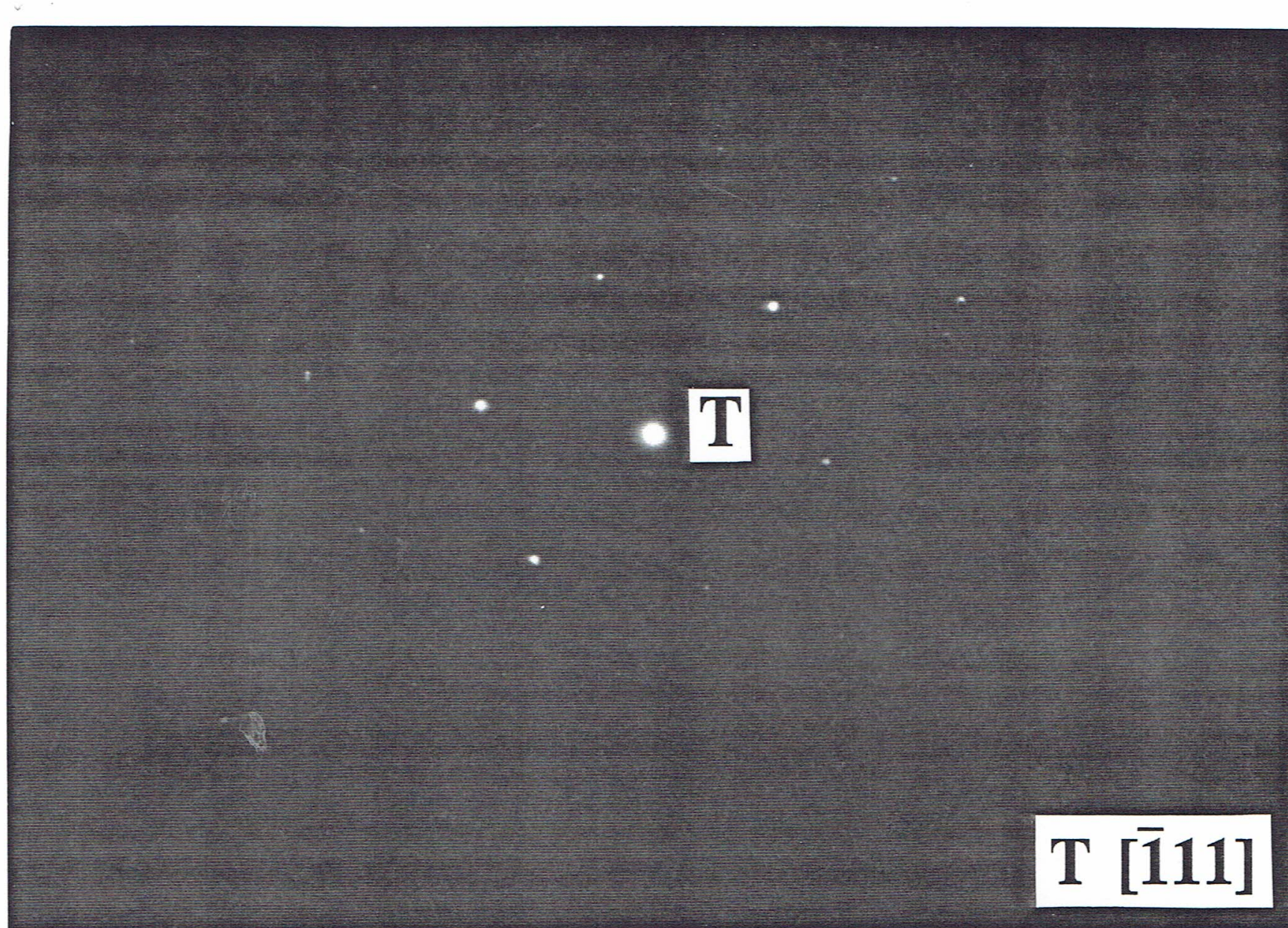

Tiqume Gow

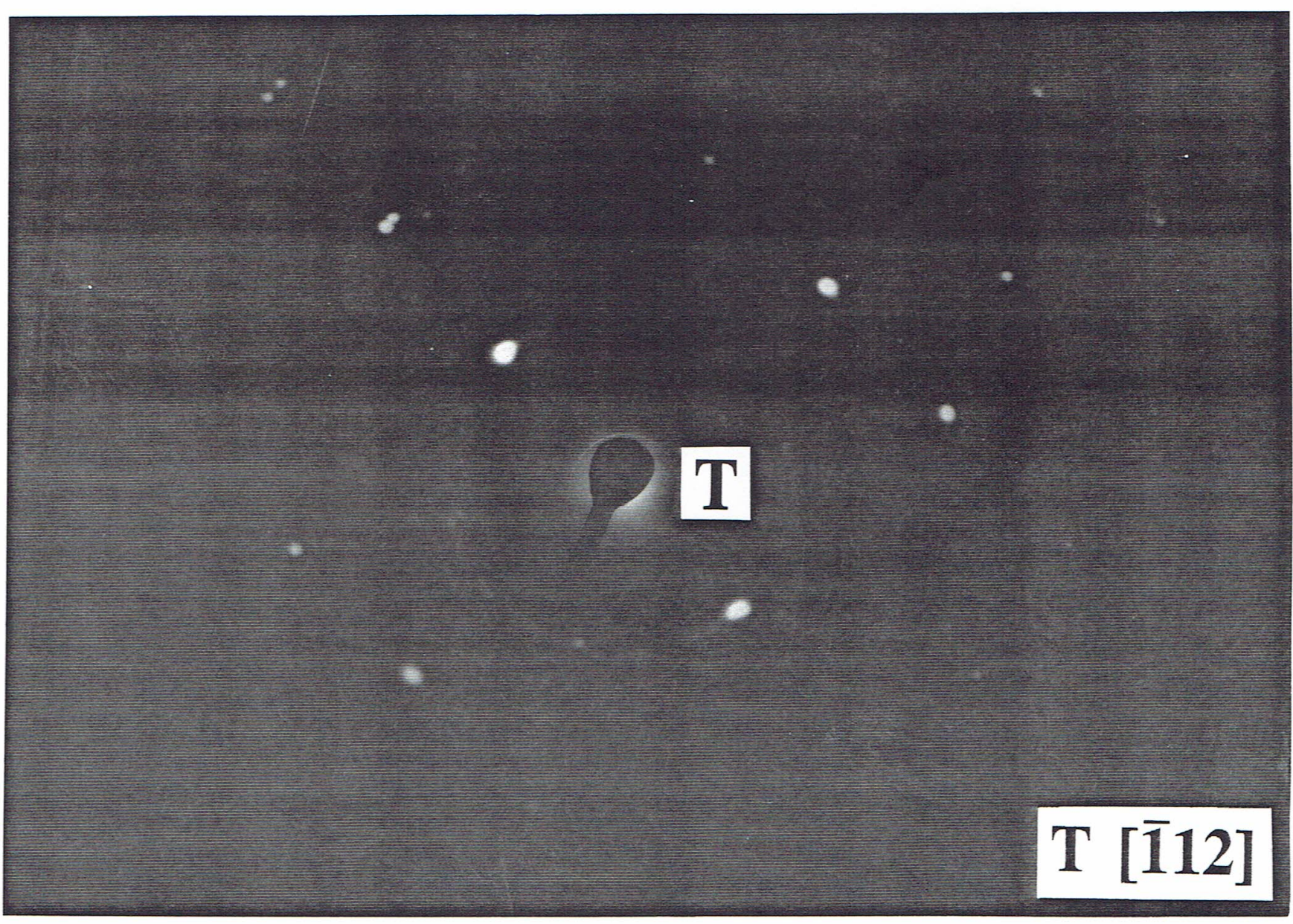

Tique 65 


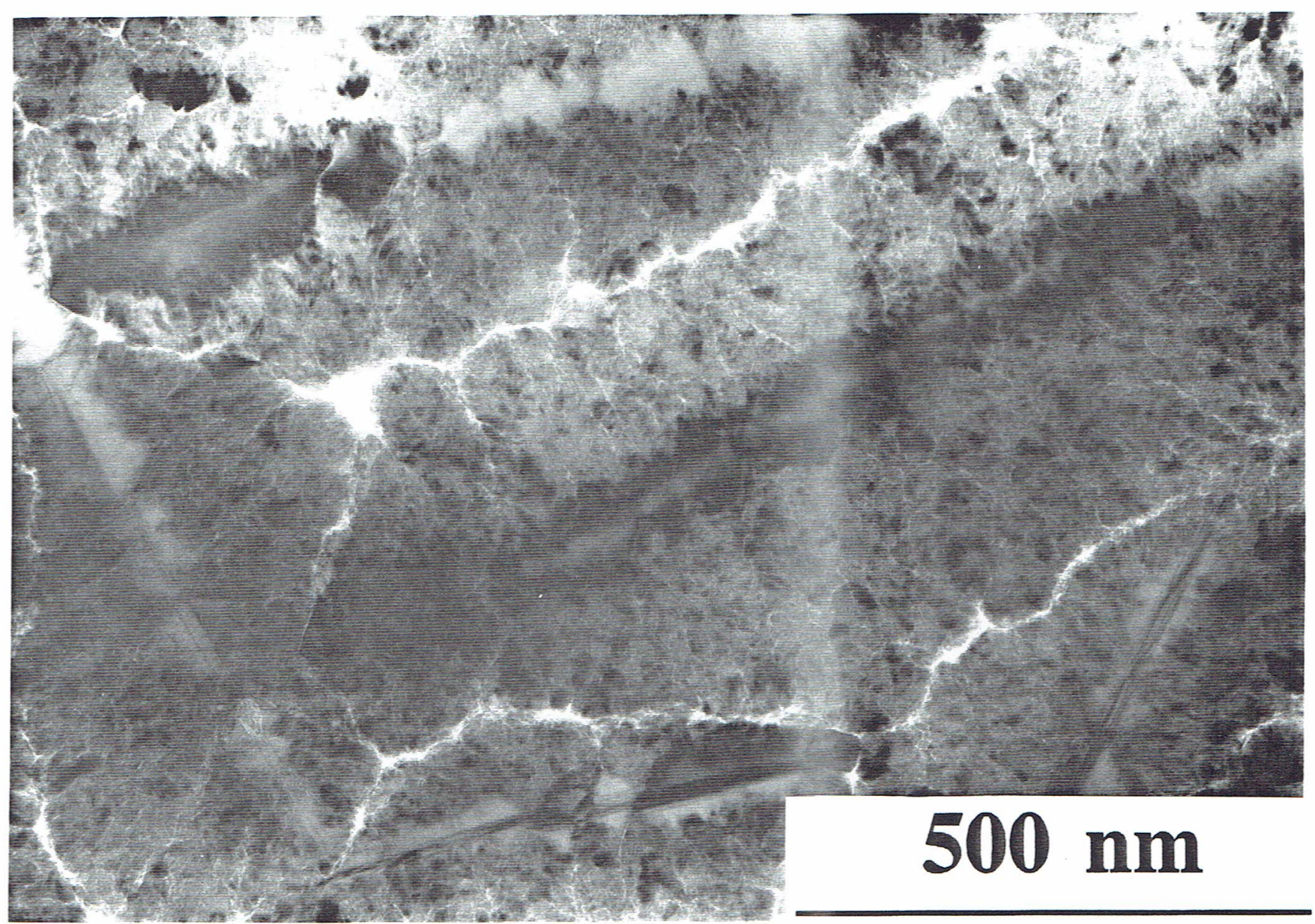
in 72

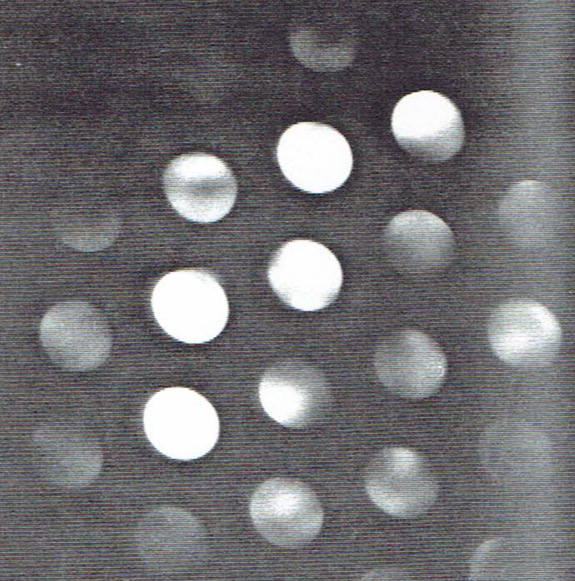

